

\section{VIAS PARA O COMÉRCIO ELETRÔNICO}

| POR PRISCILA LACZYNSKI DE SOUZA MIGUEL E PAULO FERNANDES

\section{As vendas on-line possibilitam melhorar a oferta e reduzir gastos, mas é preciso investir em novos sistemas de logística para gerenciar informações e otimizar transporte.}

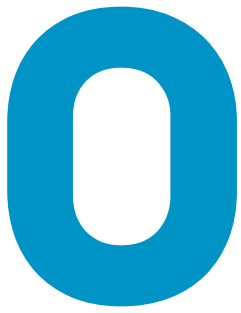

varejo tem ocupado o lugar da indústria como coordenador e direcionador das atividades de logística nas cadeias produtivas. Esse novo enfoque tem suas particularidades. Diferentemente da empresa industrial, o varejista tem relação direta com o consumidor. Mais do que o processo operacional, sua prioridade é satisfazer ao cliente. Enquanto a indústria se concentra em eficiência, o varejo trabalha com responsividade, isto é, velocidade, flexibilidade e agilidade no momento do atendimento.

Hoje, é necessário oferecer um portfólio mais diversificado de produtos ao consumidor, o que exige gerenciar um número superior de itens no estoque (SKU, ou stock keeping units) em quantidades menores. Com isso, a complexidade da logística aumenta. Em comparação com a indústria, no varejo é preciso lidar com compras, estoques e vendas de um número muito maior de itens e, ao mesmo tempo, com um volume muito menor de cada um deles.
0 uso do canal eletrônico permite aumentar a variedade e a disponibilidade de produtos para

$$
\begin{gathered}
\text { os clientes sem que seja } \\
\text { preciso estocá-los. }
\end{gathered}
$$

Antes, o varejo tinha a vantagem de não precisar cuidar dos processos de entrega dos produtos, uma vez que o consumidor ia ao ponto de vendas para realizar a compra. Com o início do e-commerce, no entanto, essa realidade mudou. Segundo a Associação Brasileira de Comércio Eletrônico (ABComm), o e-commerce nacional deve ter crescimento de $12 \%$ em 2017 em relação a 2016. Essa mudança traz novos desafios e oportunidades para a área de logística. 


\section{CRESCIMENTO DE E-CONSUMERS NO BRASIL (EM MILHÕES)}
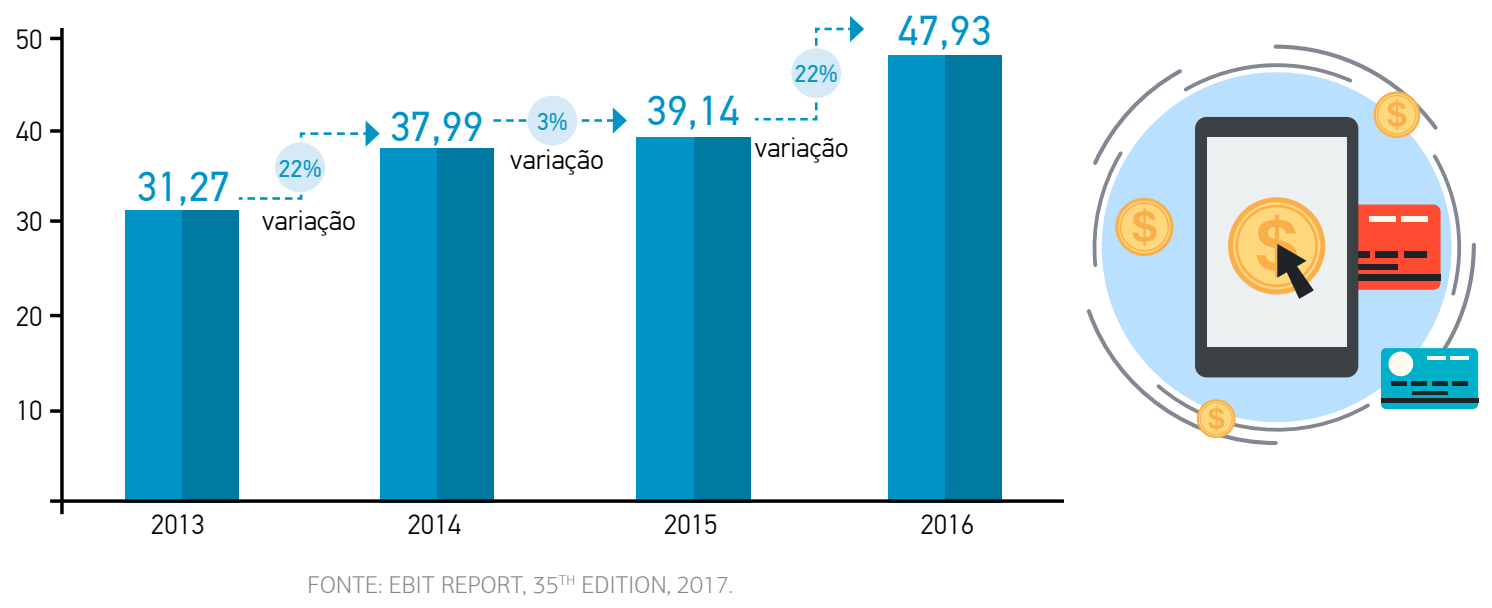

\section{OPORTUNIDADES}

$\mathrm{O}$ uso do canal eletrônico permite aumentar a variedade e a disponibilidade de produtos para os clientes sem que seja preciso estocá-los. Com boas parcerias para que os fornecedores mantenham um estoque mínimo de produtos e atendam aos pedidos rapidamente, o varejista pode contar com uma gama muito mais diversificada de produtos sem necessidade de ter inventário. $\mathrm{O}$ e-commerce ainda permite oferecer pré-lançamentos, ou seja, produtos que ainda não estão em fase de comercialização. Ao iniciar a venda de forma antecipada, é possível planejar melhor a demanda e garantir o atendimento ao cliente no prazo prometido.

Outra alternativa viabilizada pelo e-commerce é a entrega direta do fornecedor para o cliente. Conhecida como dropshipment, essa operação consiste em redirecionar o pedido firmado pelo cliente para o fornecedor, que se encarrega de fazer o embarque em nome do varejista. A Amazon.com, por exemplo, recebe seus pedidos e transmite-os a seus fornecedores, que providenciam a entrega sem que haja fluxo físico passando pela varejista. Isso permite reduzir tempo de entrega e investir em estoque. Há, no entanto, que se adequar o processo fiscal, para que seja possível emitir a nota fiscal adequadamente.

Com o e-commerce, há ganhos em custos de estoque $\mathrm{e}$ também de instalações. Ao oferecer produtos pelo site, a empresa não tem necessariamente de investir em lojas físicas. Torna-se viável centralizar a gestão do estoque, o que permite manter um inventário mais enxuto e controlado, reduzindo gastos que representam uma parcela considerável dos custos de uma empresa.

\section{A logística de e-commerce traz} desafios tanto para as operações internas da organização como para o processo de entrega em grandes centros urbanos.

\section{DESAFIOS}

Não obstante, a logística de e-commerce traz desafios tanto para as operações internas da organização como para o processo de entrega em grandes centros urbanos. É especialmente sensível na chamada Last Mile, ou última milha, etapa em que as mercadorias saem de um centro de distribuição para alcançar o cliente final. Trata-se do momento decisivo, em que a empresa fica sob o escrutínio dos consumidores.

Para garantir a satisfação do cliente, há necessidade de investimento em um sistema de informação robusto que garanta visibilidade e rastreabilidade do pedido, bem como para coordenar a disponibilidade de produtos com os fornecedores. Não dá para oferecer um produto e prometer entregá-lo em dois dias se o controle de materiais não for extremamente eficiente.

Outro desafio refere-se ao transporte. Em linhas gerais, os custos são baixos no transporte quando se trabalha com cargas completas e poucos pontos de parada. $\mathrm{O}$ e-commerce desafia esse modus operandi, pois exige entregas fragmentadas em 


\section{EXEMPLOS DE SOLUÇÕES PARA LOGÍSTICA URBANA}

Diversos países têm estimulado e priorizado o desenvolvimento de soluções logísticas diferenciadas para as cidades. Alguns exemplos são:

1 - Centros urbanos de carga: presentes na França e na Holanda, são parques logísticos periféricos e próximos a aeroportos, portos e rodoanéis que visam racionalizar as entregas de Last Mile, etapa em que as mercadorias saem de um centro de distribuição para alcançar o cliente final. 0 objetivo é reduzir a quantidade de veículos nos grandes centros. Nesses parques, por exemplo, os grandes caminhões de carga podem remanejar as mercadorias para que veículos de menor porte façam as entregas nas cidades;

2 - Freight villages: presentes, por exemplo, na Espanha, são pontos de transferência intermodal localizados ao redor dos grandes centros, permitindo consolidação e racionalização de frete, viabilização de logística colaborativa entre operadores e promoção de sinergias entre empresas e operações distintas;

3 - Hotéis urbanos: presentes, por exemplo, em Paris, funcionam como um armazém que subloca espaços;

4 - Vias que permitem acesso seguro: estruturação de sistema viário que leva em consideração os diferentes usuários - pedestres, ciclistas, usuários de transportes coletivos etc.;

5 - Entregas em horários diferenciados: presentes por exemplo, em São Paulo, são planejadas entregas em horários de menor fluxo (noite e madrugada);

6 - Estudos de logística com base em polos geradores de entrega: são pesquisas para soluções de transporte que levam em conta o movimento em centros comerciais, shopping centers etc.

Novas soluções, muitas propostas por startups de logística, também podem contribuir para mitigar os problemas urbanos relacionados ao transporte de cargas.

Alguns países têm estimulado soluções baseadas no conceito de economia colaborativa, tais como:

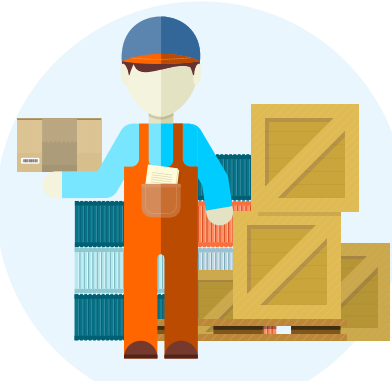

1 - Crowdshipping: pessoas registram-se em uma plataforma e realizam a entrega de acordo com sua disponibilidade;

2 - Compartilhamento de transporte: mais de uma empresa trabalha a gestão compartilhada de suas entregas para maximizar a produtividade de distribuição;

3 - Diversificação de modais de entrega final: uso de motos, bicicletas, e mesmo pedestres, para cobrir a distância final até o cliente.

Outra alternativa é o ponto de entrega coletiva (ou locker), que viabiliza a entrega pelo prestador de serviço logístico em um ponto mais centralizado, com melhor acesso e flexibilidade de horário de recebimento, promovendo maiores taxas de sucesso de entrega.

muitos destinos, resultando em maiores valores dispendidos em fretes e mais atenção para gerenciar as rotas.

Não é óbvio, também, gerenciar a devolução de produtos por parte dos clientes. A empresa precisa desenhar um processo de logística reversa para coletar retorno em diferentes pontos. O planejamento de transporte, nesse caso, não obedece aos mesmos critérios da logística direta. A coleta é mais demorada e depende da embalagem adequada, o que implica mais dificuldade de roteirização dos deslocamentos. Além disso, primeiramente é necessário receber o produto para autorização de novo envio. Esse tem sido um dos principais gargalos das empresas que operam no e-commerce. E não se trata de uma exigência apenas regulatória (por lei, o cliente que compra on-line pode devolver o produto em até sete dias a partir do recebimento), mas de uma necessidade de garantir um bom serviço e manter a reputação elevada. 


\section{CRESCIMENTO DA POPULAÇÃO URBANA MUNDIAL}

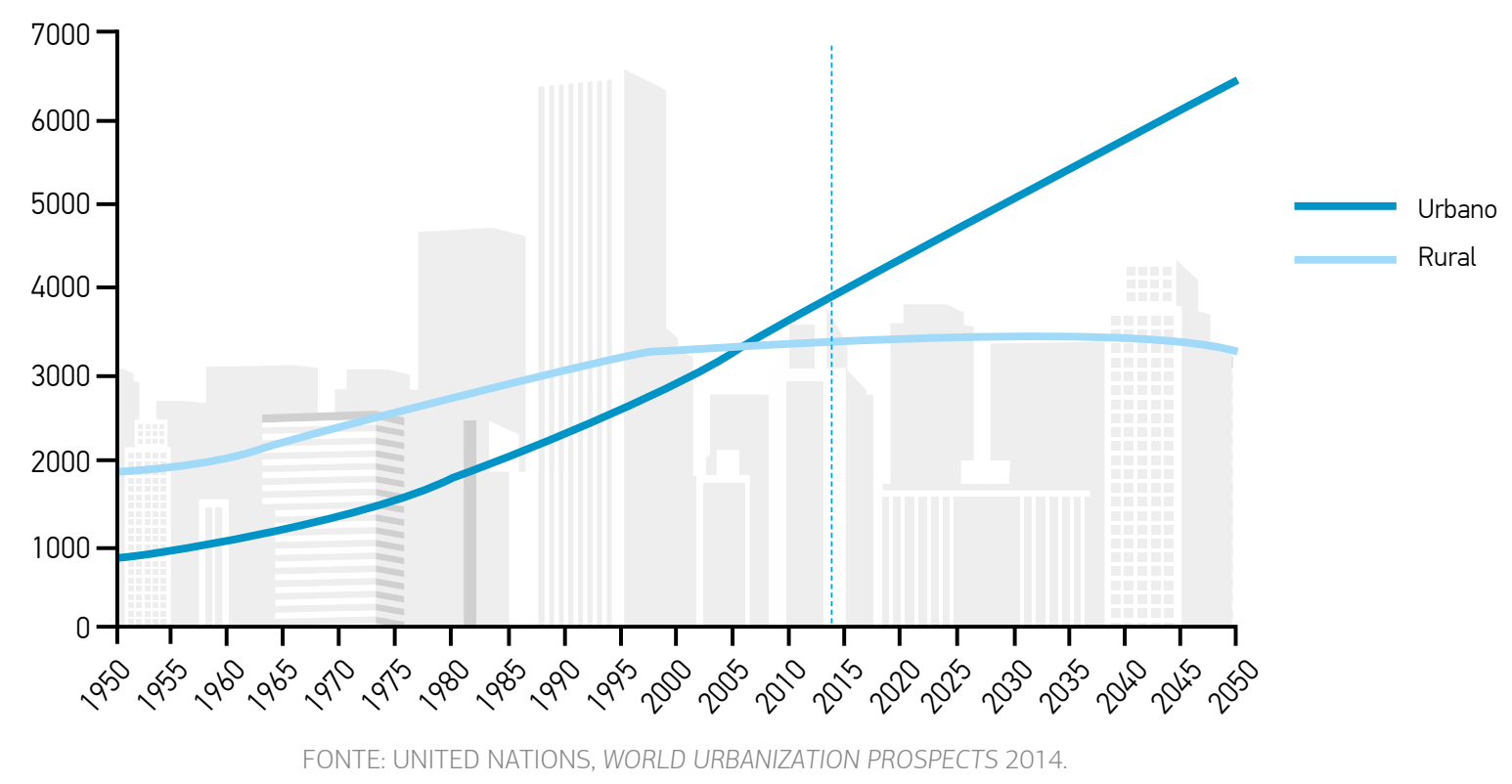

No Brasil, muitos clientes optam por não comprar on-line, por ainda não terem certeza do processo de devolução, mas em países mais desenvolvidos, como a Alemanha, o volume de retorno pode chegar a $40 \%$ das compras. Empresas como Amaro.com e Netshoes.com, por exemplo, garantem a troca gratuita e já incorporaram esse processo em sua logística.

Quanto à gestão e à efetivação, a logística urbana tem ainda particularidades que a tornam mais difícil - e usualmente mais custosa: infraestrutura; conflito de prioridades com transporte público, de pedestres e de veículos particulares; crescente número de restrições a veículos de carga, para citar alguns empecilhos. Pesquisa anual do Serviço Brasileiro de Apoio às Micro e Pequenas Empresas (Sebrae) aponta a logística urbana como o segundo principal desafio das lojas de e-commerce no Brasil, ficando atrás apenas de tributação.

Os impactos decorrentes da entrega urbana de carga afetam a qualidade de vida nas cidades, resultando em mais poluição do ar, geração de ruídos e acidentes nas vias. Com o contínuo aumento na concentração da população em áreas urbanas, esses efeitos negativos tendem a crescer.

\section{SAÍDAS}

As iniciativas que buscam aumentar eficiência das cadeias de distribuição e reduzir os impactos negativos da logística

\section{Para diminuir o impacto das entregas nas grandes cidades, as empresas precisam encontrar soluções conjuntas com setor público, prestadores de serviços, universidades e ONGs.}

urbana incluem: revisão das políticas públicas de restrição de acesso de veículos de carga; coordenação de ações entre transporte de passageiro (público e privado) e transporte de carga; priorização de uso de via conforme região e horário; estímulo a opções de entrega mais sustentáveis (veículos elétricos, bicicletas); desestímulo do uso de veículo particular (redução de estacionamento, pedágio urbano, malha de transporte público); e revisão de política de uso de solo para facilitar acesso a bens e serviços (reduzindo deslocamentos e viagens).

É evidente - e urgente - a necessidade de unir forças, capacidades e experiências para atuar nesse contexto complexo 


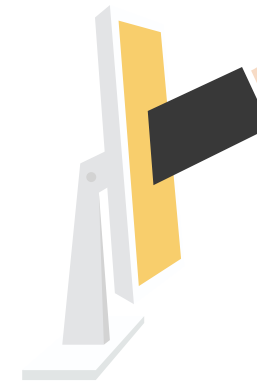

\section{CAMINHOS PARA AS PMEs}

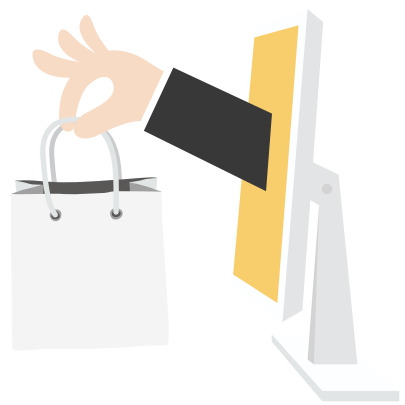

Dados de pesquisa da Forrester Research indicam que 59\% da população mundial estará on-line até 2020 e que o comércio eletrônico crescerá 15\% até o mesmo ano. Nesse mercado promissor, cada vez mais competitivo e com desafios que vão desde a escolha da plataforma ideal para o website até a concorrência sem limites geográficos, as pequenas e médias empresas (PMEs) buscam o melhor caminho para se destacarem. Sairão vencedoras aquelas que mais rapidamente conseguirem amadurecer suas técnicas de relacionamento com o consumidor, do começo até o fim do processo de compra, incluindo a entrega impecável.

O planejamento logístico torna-se tão importante quanto a qualidade e o preço das mercadorias. Em uma transação virtual, o consumidor paga pelo produto antes mesmo de tocá-lo. Por isso, o primeiro contato físico do cliente ao receber sua encomenda é a chave para o coroamento da experiência de compra. A estocagem, a embalagem e o transporte corretos da mercadoria ganham importância nesse processo.

Ainda nesse contexto, oferecer ao cliente visibilidade em tempo real do trajeto do pacote é outro ponto de extrema relevância, sendo o trecho do centro de distribuição para a entrega final (last mile) o mais significativo. De acordo com um estudo da International Post Corporation (IPC), para $86 \%$ dos consumidores globais, o out for delivery é a fase mais importante do rastreamento.

0 cumprimento de prazos e a agilidade da entrega também são fatores determinantes. Segundo a pesquisa "Comércio global na economia digital: oportunidades para pequenos negócios", conduzida em 2016 pela inglesa Harris Interactive a pedido da FedEx Express, 50\% das PMEs entrevistadas no Brasil que geram receita via e-commerce relataram que para expandir seus negócios é necessário um serviço de entrega mais rápido e eficiente - o que as levaria até a pagar por um serviço premium por isso. No caso de vendas internacionais, é importante considerar os aspectos culturais, legislativos e tributários de cada país.

O e-commerce já passou de tendência para realidade - e usando a logística como aliada. Com isso, as PMEs podem ter uma vantagem estratégica importante nesse mercado, cada vez mais competitivo.

EDUARDO ARAÚjO > Diretor de Logística da FedEx no Brasil > eduardo.araujo@fedex.com

da logística urbana. A cooperação não deve ser apenas entre o público e o privado, mas também entre os prestadores de serviços (compartilhamento, consolidação), incluindo universidades (estudos de viabilidade, pesquisa de impacto) e entidades não governamentais (inclusão dos demais stakeholders). Considerando a velocidade do crescimento da população nas cidades brasileiras, podemos dizer que já estamos atrasados.

São muitos os desafios para quem pretende ter o canal on-line como alternativa na distribuição. Para superar os obstáculos e alavancar o negócio, as empresas devem evitar adaptar sua logística tradicional para o comércio eletrônico e pensar em uma nova estratégia, planejando e configurando seus processos. Isso significa buscar soluções inovadoras e estabelecer parcerias com outros stakeholders, tais como operadores logísticos e pontos de coleta.

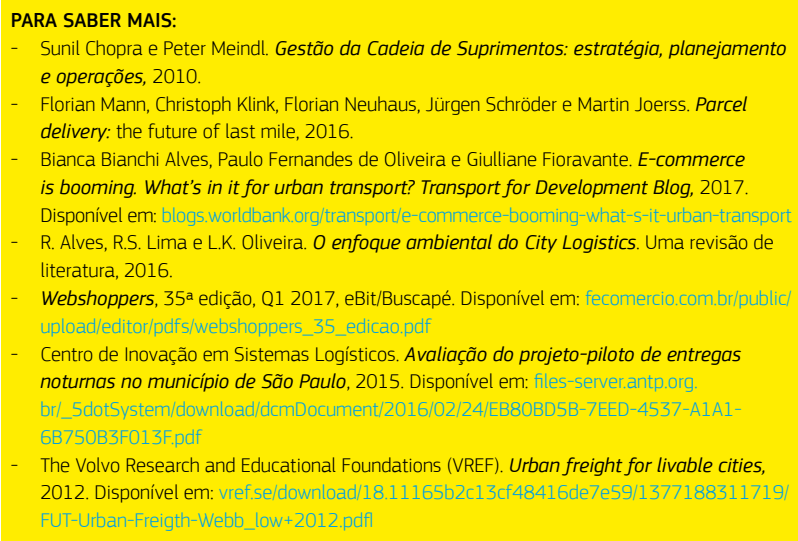
is booming. What's in it for urban transport? Transport for Development Blog, 2017 Disponivel em: blogs.worldbank.org/transport/e-commerce-booming-what-s-it-urban-transpor R. Alves, R.S. Lima e L.K. Oliveira. O enfoque ambiental do City Logistics. Uma revisão de literatura, 2016.

Webshoppers, 35a edição, Q1 2017, eBit/Buscapé. Disponível em: fecomercio.com.br/public/ upload/editor/pdfs/webshoppers_35_edicao.pdf

Centro de Inovação em Sistemas Logísticos. Avaliação do projeto-piloto de entregas noturnas no município de São Paulo, 2015. Disponivel em: files-server.antp.org. br/ 5dotSystem/download/demDocument/2016/02/24/EB80BD5B-7EED-4537-A1A1 6B750B3F013F.pdf The Volvo Research and Educational Foundations (VREF). Urban freight for livable cities, 2012. Disponivel em: vref.se/download/18.11165b2c13cf48416de7e59/137718831171 FUT-Urban-Freigth-Webb_low+2012.pdf

PRISCILA LACZYNSKI DE SOUZA MIGUEL > Professora FGV EAESP Coordenadora GVcelog, FGV EAESP > priscila.miguel@fgv.br PAULO FERNANDES > Pesquisador colaborador GVcelog, FGV EAESP > paulofernandes@gvmail.br 